\title{
A Note on the Seiches of Alligator Harbor, Florida*
}

\author{
Takashi ICHIYe and George B. DowLING**
}

\begin{abstract}
The tidal records of Alligator Harbor of two months in summer of 1952 are analyzed. The frequency of occurrence of seiches and their amplitudes and energy distributions against periods are determined. Several methods of computing periods of seiches are applied to the bay. A dynamical explanation for initiation of oscillations of different modes in a bay is proposed. Correlograms and power spectra of sea level deviations from tides are determined in several parts of the records with conspicuous amplitudes. Relationships between seiches and meteorological conditions are discussed.
\end{abstract}

\section{Introduction}

Alligator Harbor on the northern Gulf coast of Florida has been the object of various kinds of oceanographic studies since the establishment of Marine Laboratory of Florida State University (OLson, 1955). However, systematic researches on tides and related phenomena have not been accomplished yet. This report is a preliminary one for more complete studies which are now under planning.

Alligator Harbor is a shallow estuary with the mean low water depth of about 4 feet, length of 4 miles and width of $1 \frac{1}{4}$ miles (Fig. 1). The tides were occasionally recorded in a weekly chart at a pier of Marine Laboratory. Only the records from July 13 to September 13 of 1952, during which recording was operated with a daily chart, are suitable for studying the seiches. Therefore the present study is mainly based on these records.

\section{Statistics of occurrence of the seiches}

In the records mentioned above all the oscillations with amplitudes larger than 0.3 in. $(0.76 \mathrm{~cm}$, half a division of scales of recording papers) are picked up and the periods are determined as the intervals from peak to peak. (When oscillations consist of a peak and a trough only, the time between peak and trough is doubled.) The numbers of

* Received Mar. 28, 1960; Contribution No. 153 from Oceanographic Institute, Florida State University.

** TI, Oceanographic Institute, Florida State University: GBD, US Navy Mine Defense Labo. ratory, Panama City, Florida. oscillations (one wave from peak to peak is counted as one), the sum of amplitudes and the sum of squared amplitudes for different intervals of periods are shown in Table 1 .

The table indicates that oscillations with periods of about one hour were generated most frequently, while the sum of squared amplitudes which are considered as proportional to energy of oscillations shows the maximum for periods of about 2.5 hours. This is due to the condition that the oscillations with longer periods of 2.5 hours occurred less frequently but had larger amplitudes than those with periods of one hour. This is also seen in the distribution of the average amplitude obtained by dividing the sum of amplitudes by the numbers of oscillations in Table 1.

These crude statistics suggest that there are two predominant oscillations in the bay and that the periods of oscillations are widely scattered.

\section{Computation of periods of seiches}

Alligator Harbor is relatively simple in its geometry, with an elongated shape. However, shallowness and a sand bar across the mouth make computation of the periods of seiches complicated (Fig. 1A).

In a bay with an open mouth, the common type of standing waves is that which has a nodal line across the mouth and an antinode at the closed end of the bay. This type is designated here as BS (for bay seiches). However, the sand bar suggests that standing waves similar to those in a lake may be produced, because bars are often formed 


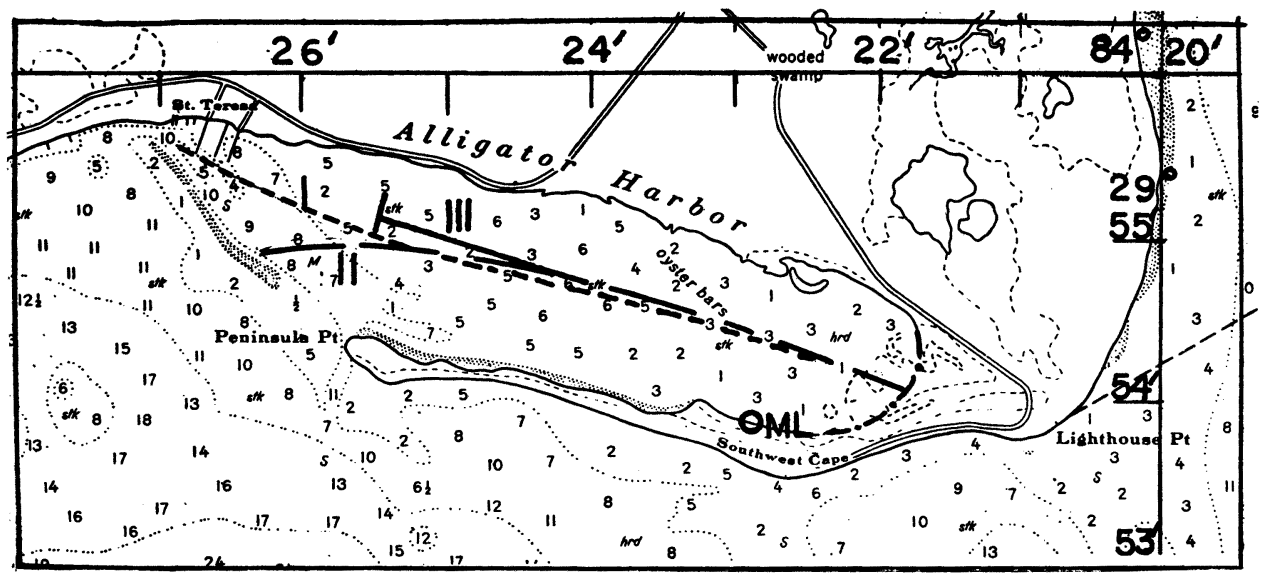

(A)

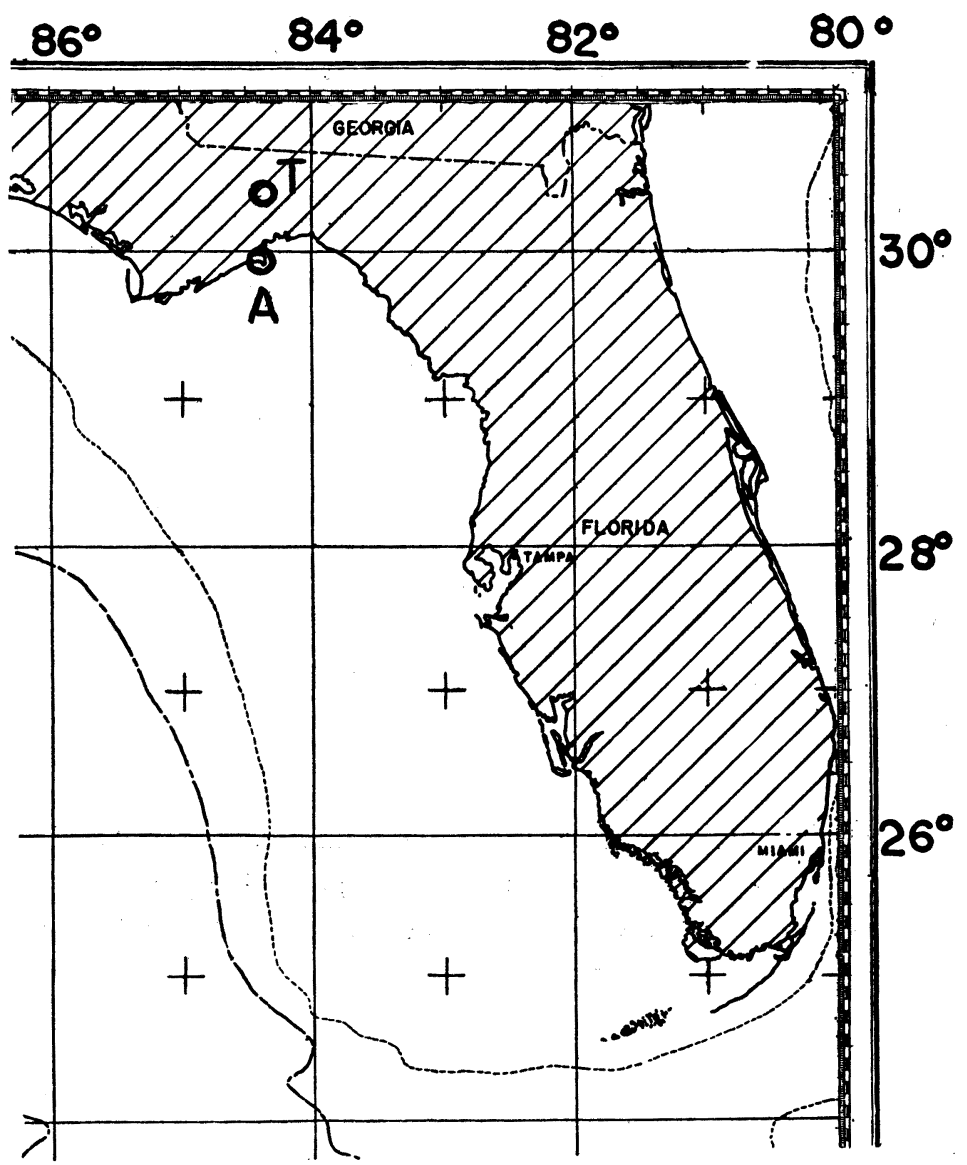

(B)

Fig. 1A. A chart of Alligator Harbor (from U. S. Coast and Geodetic Survey Chart No. 1261). $(\mathrm{ML}=$ Marine Laboratory, tidal station. The dotted line I, the broken line II and the full line III are different central lines. The chain line is an inner boundary of the bay. Fig. 1B. General map of Florida: ( $T=$ Tallahassee, $A=$ Alligator Harbor). 
Table 1.

\begin{tabular}{|c|c|c|c|c|c|c|c|}
\hline Periods (hr.) & 0.5 & 1 & 1.5 & 2 & 2.5 & 3 & 3.5 \\
\hline Numbers of Oscillations & 16 & 89 & 74 & 34 & 28 & 14 & 3 \\
\hline Total Amplitude (cm) & 36 & 227 & 236 & 137 & 149 & 91 & 21 \\
\hline Total squared Amplitude $(\mathrm{cm})^{2}$ & 53 & 469 & 980 & 671 & 1102 & 837 & 258 \\
\hline
\end{tabular}

(Periods are shown by their central value. For example, a period of 0.5 hours means those from $15 \mathrm{~min}$. to $45 \mathrm{~min}$.)

along anantinodes, where sediments accumulate owing to vanishment of currents (LETTAU, 1932). The period of the fundamental mode of BS and LS (for lake seiches) is given by Merian's formula $T=4 l / \sqrt{g h}$ and $T=2 l / \sqrt{g h}$, respectively (SvERDRUP et al., 1942, pp. 539541), in which $l$ and $h$ are length and mean depth of the bay.

The average depth of Alligator Harbor at the lowest low water determined from the chart (Fig. 1A) is $3.74 \mathrm{ft}$ (Olson, 1955). Since the mean range of tides obtained by averaging data of one year is $1.92 \mathrm{ft}$, the average depth for mean sea level and at the mean high water is $4.70 \mathrm{ft}$ and $5.66 \mathrm{ft}$, respectively. The length $l$ should be measured along the central line of the bay but it may be different for different modes of oscillations. For LS, the sand bar may become a barrier preventing free water motion. The central line can be drawn in two ways as shown in Fig. 1A (I and II). The length, then, is equal to 4.2 and $4.7 \mathrm{n}$. miles, respectively. For BS either Curve II or III may be taken as the central line (Fig. 1A). For the curve III, the node at the mouth is normal to the central line; the length of the bay becomes $3.3 \mathrm{n}$. miles and the average depth is $3.18 \mathrm{ft}$ at the lowest low water.

The periods of LS computed for all combinations of plausible values of $h$ and $l$ are tabulated in Table 2. (The corresponding periods of BS are twice of those of LS.)

This table indicates that change in depth due to different tidal stages produces variation of periods of about 30 per cent.

In order to see any differences in seiches produced at different tidal stages, numbers of oscillations, mean amplitudes and mean periods are determined for high and low
Table 2 .

\begin{tabular}{l|c|c|c}
\hline \hline & LLW & MSL & MHW \\
\hline$l=3.3 \mathrm{~nm}$ & 1.11 & 1.00 & 0.88 \\
$l=4.2 \mathrm{~nm}$ & 1.30 & 1.20 & 1.06 \\
$l=4.7 \mathrm{~nm}$ & 1.41 & 1.27 & 1.15 \\
\hline
\end{tabular}

(Periods are in hours. LLW, MSL and MHW are for lowest low water, mean sea level and mean high water, respectively).

water stages (HW and $\mathrm{LW}$ ) and for vanishing tide stages (VT) occurring around the tropical tides. The data used are the same as those used for Table 1. High or low water stages are taken as a period of about three hours around high or low water. The vanishing tides usually continued about 8 hours and occurred only 14 days during 63 days of the recording. The result is shown in Table 3 .

Table 3

\begin{tabular}{l|c|c|c}
\hline & HW & LW & VT \\
\hline No. of Oscills. & 54 & 25 & 20 \\
Mean Amp. (cm) & 3.5 & 3.3 & 6.2 \\
Mean Per. (hr) & 1.6 & 1.4 & 2.3 \\
Total Hours & 297 & 302 & 106 \\
\hline
\end{tabular}

It is seen in this table that seiches were more frequently produced at high water than at low water and that those with large amplitudes and long periods were most frequently generated during vanishing tides. In the vanishing tides, the seiches produced were mostly of BS type, while in low water they were mainly of LS type. This mixture of two types masks the effect of water depth on mean periods of seiches and thus the mean period becomes longer at high water than at low water. 
Corrections for Merian's formula owing to deviation of a bay from a rectangular shape were derived by Honda and others (1908). The corrected period is given by

$$
T_{n}=2 \ln ^{-1}\left(b_{0} / g S_{0}\right)^{1 / 2} c
$$

in which $c$ is a correction factor for Merian's period and is expressed by

$$
\begin{aligned}
c^{2}= & {\left[\int_{0}^{l}(1-\cos 2 n \pi x / l)\left(1+\Delta S / S_{0}\right)^{-1} d x\right] } \\
& \times\left[\int_{0}^{l}(1-\cos 2 n \pi x / l)\left(1+\Delta b / b_{0}\right)^{-1} d x\right]^{-1}
\end{aligned}
$$

In these equations $S_{0}$ and $b_{0}$ are mean values of cross sections and widths which are taken normal to the central line of the bay or $x$-coordinates. Deviations of these values at each section are $\Delta S$ and $\Delta b$, respectively, which are functions of $x$. $n$ represents an integer or a semi-integer which is equal to 1 or $\frac{1}{2}$ for the fundamental mode for LS or BS, respectively. Numerical computation applied to Alligator Harbor gives $c=0.859$ for $n=1$ (LS) and $c=0.954$ for $n=\frac{1}{2}$ (BS). Closeness of the values of $c$ to one indicates that the normal modes of oscillations of the bay are expressed pretty accurately by sine functions of $x$ as in a rectangular bay of a constant depth (see Appendix I).

Correction to Merian's formula due to the effect of water motion near the mouth is called "mouth correction", for which several formulae have been derived by different authors (Neumann, 1948). Most well known among them is that derived by HoNDA and others (1908) from energy principle and another by THORADE (1929) based on the idea of an equivalent length of a bay. They are given by

$$
\begin{array}{ll}
T_{c}=T_{0}\left(1+2 P b_{m} l^{-1}\right)^{1 / 2} & \text { (Honda et al.) } \\
T_{c}=T_{0}\left(1+P b_{m} l^{-1}\right) & \text { (ThoRADE) }
\end{array}
$$

in which $T_{0}$ is the period given by Merian's formula. $P$ is a numerical constant expressed by

$$
P=\pi^{-1}(3 / 2-\gamma-\log \pi b / \lambda)
$$

Then $b_{m}$ is width of the bay at the mouth, $\gamma$ is an Eulerian number equal to 0.572 and $\lambda$ is a wave length which becomes $2 l$ for LS and $4 l$ for BS.
The correction factors for Alligator Harbor are equal to 1.166 for LS and 1.219 for BS from the equation (3) and equal to 1.181 for LS and 1.243 for BS from (4). The differences of the factors determined from two formulae are slight. Combination of the mouth correction (mean of the factors obtained from two formulae) and $c$-correction obtained from (2) gives 1.01 for LS and 1.17 for BS as correction factors to Merian's periods of the bay. A larger value for BS may partly explain the fact revealed in Table 1 that the predominant periods of about $2.5 \mathrm{hr}$ of $\mathrm{BS}$ are longer than twice the periods of another predominant oscillation supposed to be of LS type.

\section{Correlation with meteorological conditions}

There were not enough data to derive definite relationships between the occurrence of seiches and meteorological conditions at Alligator Harbor. No systematic meteorological observations were done at Alligator Harbor at the time when the tidal records discussed here were obtained. However, the meteorological records of Weather Bureau Station at Tallahassee airport (Fig. 1B) and weather maps indicate that the period considered was meteorologically rather tranquil with no conspicuous disturbances except a few described below.

During July of 1952 local squalls were occasionally observed at Tallahassee and apparently caused seiches of relatively large amplitudes which were often recorded in the evening around midnight. In Fig. 2 are shown two examples of them. All records of seiches are shown after elliminating tides. Wind speed and directions at Tallahassee are plotted for the first example of July 14 to 15 . The rain squall at Alligator Harbor continued from 1830 to 1900 of July 14 accompanying the wind of 20 to $30 \mathrm{~m}$.p.h. but the data at Tallahassee indicates that this squall was between 1600 and 1630 with the wind of merely 10 m.p.h. or less. In the second example of July 26, the squall began at about 2320 and brought the wind of 40 m.p.h. at Alligator Harbor. It should be noted that the seiches were recorded several hours before the squall 
actually attacked Alligator Harbor in both examples. These forerunners might have been caused by long waves which were ini-
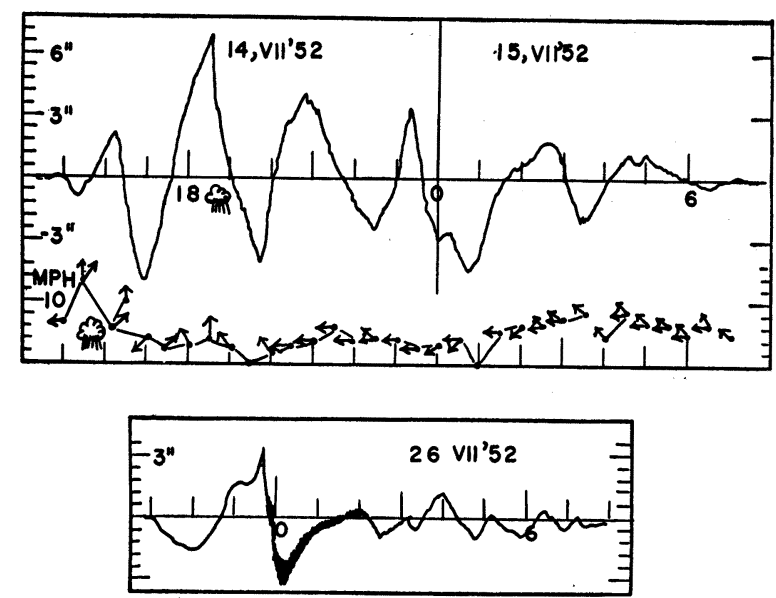

Fig. 2. Examples of seiches produced by local showers. (Wind speed in $\mathrm{mph}$ and wind direction at Tallahassee are plotted for the period of 14 to 15 July.)

tiated in the open sea and propagated faster than the squall (ICHIYe, 1950).

Three examples which are supposed to be due to distant meteorological disturbances are shown in Fig. 3 to 5 with weather charts for the occasions. Usually the seiches which are caused by distant origins continue longer than those due to local origins. The seiches of August 28 to 29 plotted in Fig. 3 seem to be due to the hurricane which advanced northwards off the Atlantic coast of Florida. The records at Tallahassee indicate that this hurricane brought only occasional rains and winds of around 10 m.p.h. from the evening of 28th through 29th. The seiches of September 11 to 13 might have been caused by a weak tropical low which appeared southeast of Florida on 10th and advanced northeastwards through 11th. Obviously intensity of this low was much weaker and its duration was shorter than the hurricane of the previous example. However, the seiches caused by both disturbances had similar order of amplitudes and duration.

The last example of Fig. 5 is taken from records of September 14 to 16 of 1953 (which are not discussed in Section 2). This example gives the seiches caused by a stationary front across the northern boundary of Florida which brought winds less than 10 m.p.h. at Tallahassee throughout the period. However, long duration of seiches of relatively large amplitudes suggests that this front might have been rather intense in the open Gulf.

\section{Correlograms and power spectra}

Whittle has computed correlograms and periodgrams of series of the water level which was read at 15-second interval from a seiche record (1954). In this study, the fluctuation of sea level due to seiches was obtained from conventional tidal records by eliminating the tides. Therefore, readings of the sea level must be taken at 15 -minute interval. Then, in order to obtain statistically significant results, long series of records are needed. On the other hand, it is desirable to select an interval of records for which a cause of the

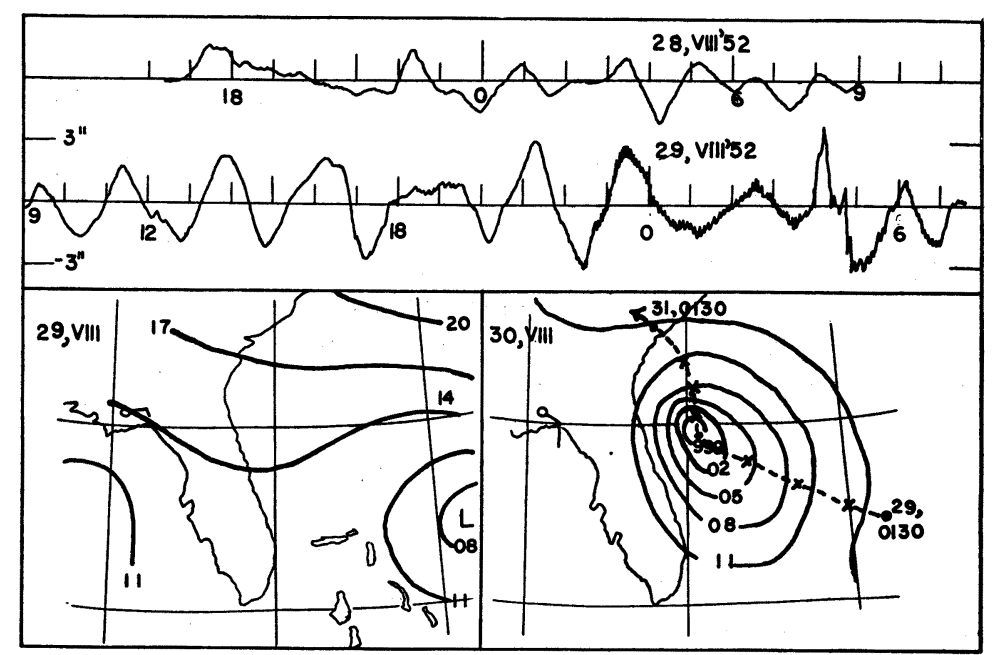

Fig. 3. An example of seiches produced by a hurricane. Weather maps are taken from U. S. Weather Bureau Daily Charts. The time of observation is at 0130 EST. Successive centers of the hurricane are indicated with crosses and closed circles at 6-hour interval). 


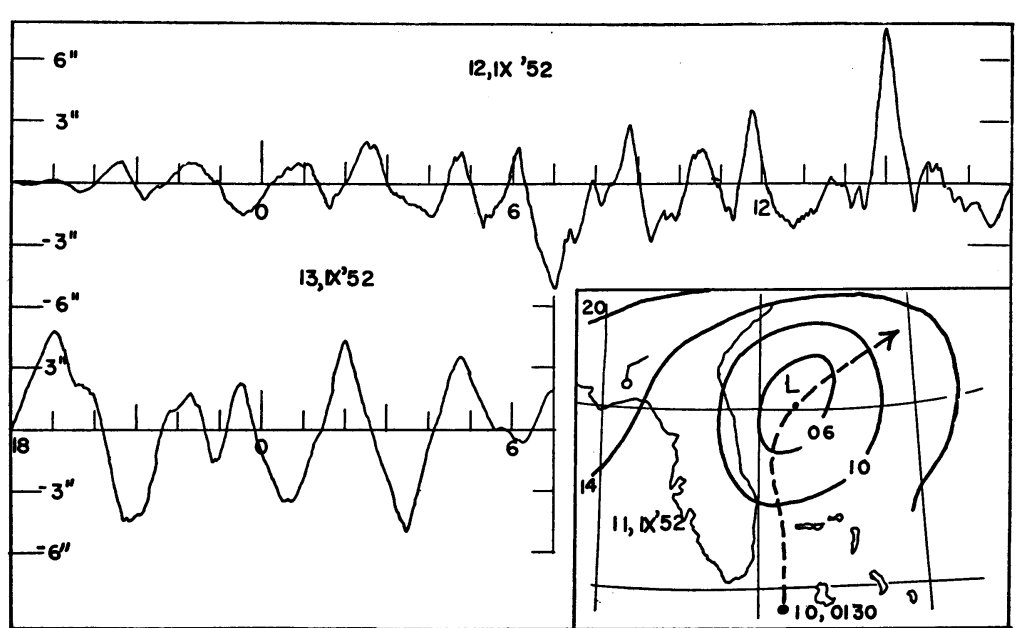

Fig. 4. An example of seiches produced by a tropical low. (See legend of Fig. 3.)

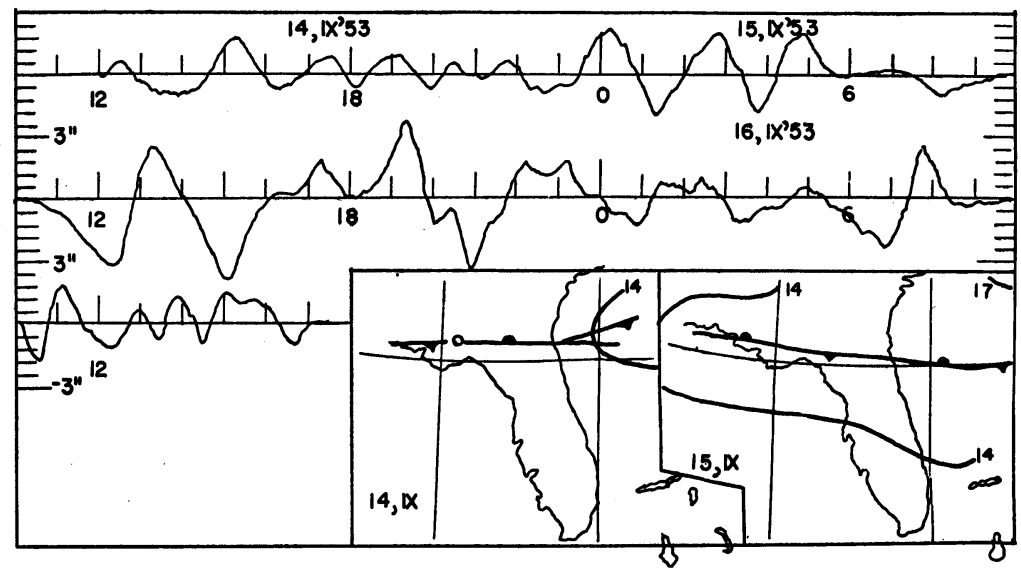

Fig. 5. An example of seiches produced by a stationary front. (See legend of Fig. 3 .

seiches can be specified, for the purpose of knowing the relationships between the seiches and meteorological disturbances. Four intervals of the records which showed conspicuous fluctuations of sea level are selected so as to satisfy these two requirements as nearly as possible.

The first interval (I) consists of records from 1300 of July 13 to 0815 of July 18, 1952. This represents the period when local showers of short duration produced seiches almost every evening and night (Fig. 2). The second interval (II) gives an example of seiches caused by a distant hurricane (Fig. 3). The third example (III) corresponds to seiches due to a weak tropical low (Fig. 4). The fourth interval (IV) is an example of seiches due to a stationary front (Fig. 5).

The sea level $X_{t}$ is read at 15-minute interval from the tidal records for each of these examples. The autocovariance $C_{s}$ is computed from

$$
\begin{aligned}
C_{s}= & \frac{1}{n-s} \sum_{t=1}^{n-8}\left(X_{t}-\bar{X}_{t}\right) \\
& \times\left(X_{t+s}-\bar{X}_{t+8}\right)
\end{aligned}
$$

where $\bar{X}_{t}$ is the average of $X_{t}$ for $t=1$ to $t=n-s$. Correlograms can be computed from the relation $R_{s}=C_{s} / C_{0}$ and they are obtained in each interval for values of $s$ up to 24 .

There are two kinds of formula for power spectra derived from correlograms. One formula has been given by Blackman and TukeY (1958). They defined raw spectral density as

$$
\begin{aligned}
V_{s}= & C_{0} \\
& +2 \sum_{q=1}^{q-m-1} C_{q} \cos (q s \pi / m) \\
& +C_{m} \cos s \pi
\end{aligned}
$$

and refined spectral density as

$$
\begin{aligned}
& U_{s}=\frac{1}{2} V_{s-1}+\frac{1}{2} V_{s}+\frac{1}{4} V_{s+1} \quad(1 \leqslant s \leqslant m-1) \\
& U_{0}=\frac{1}{2}\left(V_{0}+V_{1}\right) \\
& U_{m}=\frac{1}{4}\left(V_{m-1}+V_{m}\right)
\end{aligned}
$$

The other formula which has been applied to a seiche record by Whittle (1954) was given by BARTLETT $(1950,1955)$ as

$$
I_{s}=C_{0}+2 \sum_{q=1}^{m-1} C_{q}(1-q / m) \cos (q s \pi / m)
$$

These values of $V_{s}, U_{s}$ and $I_{s}$ represent the spectral density at a period of $2 \mathrm{m \Delta t} / \mathrm{s}$, in 
which $\Delta \mathrm{t}$ is an equispaced interval for $X_{t}$.

Correlograms $R_{s}$ and spectral densities $V_{s}$, $U_{s}$ and $I_{s}$ are tabulated in Table 4 and all of them except $V_{s}$ are plotted in Fig. 6. The correlogram of the interval II which corresponds to the seiches produced by a hurricane is distinguished from those of other intervals. It indicates more regular wave forms with less damping than the other three. Damping is most conspicuous in the correlograms of the interval I, although this has more regular wave forms than those of III and IV. Such differences in correlograms may be explained from statistical natures of disturbing forces which produced the seiches. In the example II, long waves generated in the hurricane area would arrive at the coast of the northern Gulf with relatively regular wave forms as they traveled long distance from the source. Thus the seiches produced by them had also a regular spectrum. On the other hand, in other occasions the disturbing forces, particularly such local showers as in the example $I$, were random and

Table 4.

\begin{tabular}{|c|c|c|c|c|c|c|c|c|c|c|c|c|c|c|c|}
\hline \multicolumn{4}{|c|}{$R_{8}\left(\times 10^{3}\right)$} & \multicolumn{4}{|c|}{$V_{s}\left(\right.$ in $\left.\mathrm{cm}^{2}\right)$} & \multicolumn{4}{|c|}{$U_{8}\left(\mathrm{im} \mathrm{cm}^{2}\right)$} & \multicolumn{4}{|c|}{$I_{s}\left(\right.$ in $\left.\mathrm{cm}^{2}\right)$} \\
\hline$s$ & I & II & III IV & I & III & III & IV & I & II & III & IV & I & II & III & IV \\
\hline 0 & & & & 24 & 10 & 23 & 8 & 30 & 19 & 19 & 8 & 0 & 4 & 30 & 4 \\
\hline 1 & 783 & 709 & $747 \quad 719$ & 10 & $11^{*}$ & 51 & 7 & 17 & 2 & 30 & 10 & 13 & 3 & 28 & 9 \\
\hline 2 & 380 & 190 & 305308 & 24 & 19 & $5 *$ & 18 & 46 & 11 & 45 & 19 & 26 & 12 & 47 & 20 \\
\hline $3-$ & -269 & $-318-$ & $-23-35$ & 124 & 15 & 138 & 32 & 109 & 32 & 94 & 35 & 108 & 27 & 109 & 33 \\
\hline $4-$ & -338 & $-304-$ & $-217-260$ & 171 & 78 & 104 & 58 & 141 & 62 & 105 & 41 & 144 & 57 & 103 & 42 \\
\hline $5-$ & -523 & -547 & $-343-408$ & 103 & 77 & 72 & 15 & 104 & 56 & 73 & 27 & 100 & 54 & 66 & 27 \\
\hline $6-$ & -542 & -512 & $-357-460$ & 39 & $9 *$ & 44 & 19 & 45 & 20 & 47 & 15 & 51 & 14 & 57 & 15 \\
\hline $7-$ & -422 & $-263-$ & $-324-363$ & 33 & 21 & 25 & 6 & 52 & 18 & 40 & 15 & 34 & 12 & 30 & 10 \\
\hline 8 & -221 & -245 & $-204-195$ & 103 & 39 & 65 & 30 & 65 & 29 & 33 & 19 & 86 & 34 & 58 & 23 \\
\hline 9 & -18 & $-33-$ & $-101-73$ & 23 & 15 & $17 *$ & 6 & 39 & 19 & 12 & 12 & 22 & 15 & 12 & 20 \\
\hline 10 & 168 & $372-$ & $-49 \quad 85$ & 8 & 8 & 17 & 7 & 10 & 8 & 4 & 5 & 11 & 9 & 20 & 4 \\
\hline 11 & 239 & 512 & $44 \quad 85$ & 1 & 2 & 0 & 1 & 4 & 3 & 7 & 4 & 16 & 2 & 16 & 3 \\
\hline 12 & 228 & 264 & $161 \quad 113$ & 7 & 1 & 10 & 6 & 6 & 5 & 9 & 3 & 7 & 4 & 9 & 3 \\
\hline 13 & 170 & 138 & $230 \quad 73$ & 9 & 14 & 17 & $1 *$ & 6 & 9 & 6 & 2 & 6 & 6 & 4 & 2 \\
\hline 14 & 100 & -166 & $203 \quad 83$ & $1 *$ & 4 & $20 *$ & 1 & $2 *$ & 9 & $2^{*}$ & 1 & $1 *$ & 6 & $3 *$ & 3 \\
\hline 15 & 23 & -259 & $141-29$ & $13^{*}$ & 9 & 17 & 2 & $15 *$ & 4 & 6 & 1 & $9 *$ & 1 & 4 & 15 \\
\hline $16-$ & -42 & -491 & $127-75$ & $29 *$ & $5^{*}$ & 11 & $2^{*}$ & $21 *$ & $1^{*}$ & 9 & $1 *$ & $29 *$ & 9* & $7 *$ & $7^{*}$ \\
\hline 17 & -89 & -359 & $154-149$ & $13^{*}$ & $5^{*}$ & $3 *$ & $2 *$ & $14 *$ & $5^{*}$ & 3 & $0 *$ & $9 *$ & $5 *$ & 3 & 0 \\
\hline $18-$ & -99 & -85 & $117-185$ & $0 *$ & $5 *$ & 6 & 5 & $4 *$ & $3 *$ & 3 & 4 & $1 *$ & $4^{*}$ & 2 & 2 \\
\hline $19-$ & -79 & 250 & $5-148$ & $0 *$ & 1 & $2 *$ & 7 & 0 & $0 *$ & 0 & 5 & 2 & $1 *$ & $0 *$ & 0 \\
\hline 20 & -62 & 460 & $-142-94$ & 1 & 1 & $1 *$ & 2 & 0 & 1 & 2 & 4 & 1 & 1 & 0 & 1 \\
\hline $21-$ & -32 & 527 & $-232-10$ & $0 *$ & 3 & 14 & 3 & 1 & 4 & 8 & 1 & 2 & 2 & $2^{*}$ & 2 \\
\hline $22-$ & -24 & 394 & $-306 \quad 6$ & 4 & 8 & 3 & $2^{*}$ & 6 & 6 & 5 & 1 & 6 & 5 & 1 & $1 *$ \\
\hline 23 & -18 & 59 & $-308 \quad 76$ & 15 & 4 & $2 *$ & 3 & 18 & 11 & 2 & 3 & 12 & 4 & 2 & 1 \\
\hline $24-$ & -12 & $-326-$ & $-162 \quad 209$ & 37 & 29 & 15 & 8 & 26 & 16 & 7 & 5 & 28 & 10 & 9 & 7 \\
\hline
\end{tabular}

Intervals of the data for each example: I, from 1300 July 13 to 0815 July 15 of 1952 ; II, from 1700 August 27 to 0730 August 29 of 1952; III, from 1600 September 11 to 0645 September 13 of 1952 ; IV, from 1200 September 14 to 1700 September 16 of 1953 . The asterik * behind figures of the spectral density indicates negative values. Autocorrelations are shown times 1000 and spectral densities $V_{8}, U_{8}$ and $I_{8}$ are shown in square centimeters. 

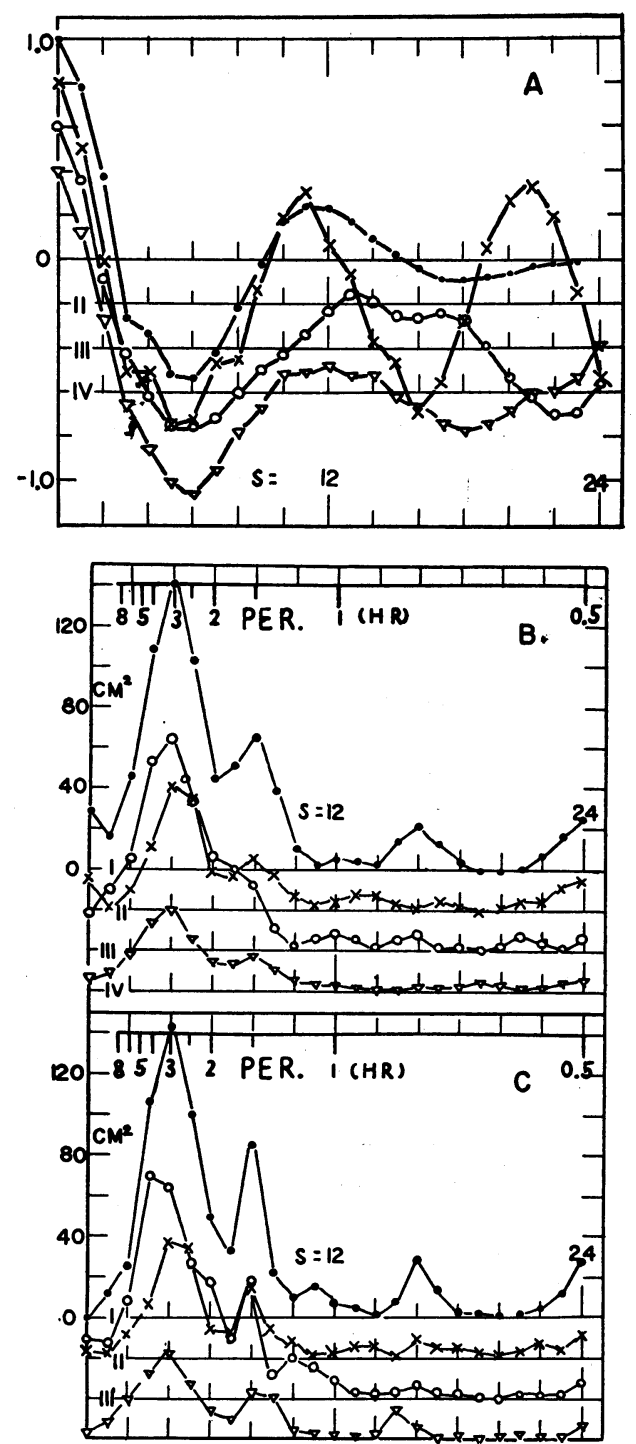

Fig. 6A. Correlograms. 6B. Spectral density $U_{s}$ defined by Blackman and Tukey (in $\mathrm{cm}^{2}$ ). 6C. Spectral density $I_{s}$ defined by Whittle (in $\mathrm{cm}^{2}$ ), I (closed circles), II (crosses), III (open circles), IV (triangles). The zero line is taken different for each group. The legend of ordinates is only for the group I. One unit of $\mathrm{s}$ corresponds to 15 minutes. Periods are shown in the upper portion of $B$ and $C$ in hours.

impulsive. Thus the spectra of the seiches include a large noise and correlograms show a conspicuous damping.

The results of spectral analysis of the correlograms do not always agree with those obtained from crude statistics of peak inter- vals of the records given in Section 2. Particularly it is striking that the most prominent period in these spectra is 3 hours and the second peak is seen at 1.5 hours, while the period of 1 hour which was the second prominent period in Table 1 cannot be recognized in the spectral density. The seiches of one hour period occurred mostly during calm days between the selected intervals. It is also noted that the spectra of I and II are similar, notwithstanding a large difference in their correlograms, except a small peak of the spectral density of $I$ at a period of about 0.8 hours which apparently corresponds to 1-hour period of Table 1 . The absolute values of the spectral intensity for dominant periods which correspond to the square of amplitudes become large for examples I and III. Thus the seiches produced by local disturbances generally attain larger amplitudes than those of a distant origin.

Since the meteorological data were not satisfactory in this study, as already stated, only one trial of statistical analysis of these data is mentioned. The seiches during the period of the example I were mainly produced by local showers. Thus the local winds observed at Tallahassee Weather Station during the period are considered to be more pertinent to seiches than those of other periods. In Table 5 are tabulated the correlograms computed from east and north components of winds observed at half hour intervals from 1300 July 13 to 1830 July 18, 1952. These correlograms indicate no periodic fluctuation of wind speed as those of the sea level. They suggest that the wind fluctuation is of normal MARKoff process (BARTLETT, 1955). When the interpretation commonly used in a theory of turbulence is applied, the average period of vortices in the atmosphere is about two to three hours, because the autocorrelations $R_{s}$ drop below the significance level for $s$ larger than 4 or 7 (LANNing and Battin, 1956). This may explain the fact that the seiches of about three hour period were generated by local meteorological disturbances which were random and impulsive.

\section{Conclusion}

More extensive data of seiches for different 
conditions are necessary with details of meteorological data. Also simultaneous recordings at several spots are desirable for determining the modes of oscillations. Instruments which filter out waves and tides are particularly needed.

Table 5. Autocorrelations for wind components.

\begin{tabular}{c|c|c|c|c|c|c|c|c|c|c|c}
\hline \hline$s$ & 1 & 2 & 3 & 4 & 5 & 6 & 7 & 8 & 9 & 10 \\
\hline $\mathrm{E}$ & 586 & 452 & 233 & 136 & 137 & 135 & 133 & 132 & 130 & 129 \\
$\mathrm{~N}$ & 563 & 372 & 278 & 250 & 293 & 273 & 198 & 196 & 192 & 134 \\
\hline
\end{tabular}

The winds were observed at half-hour intervals from 1300 July 13 to 1830 July 18, 1952 at Tallahassee Weather Station. E and $\mathrm{N}$ are for east and north components, respectively. Autocorrelations are shown times 1000.

\section{Appendix I. Derivation of correction formula to Merian's period.}

In a bay having a long axis in $x$-direction, kinetic and potential energy $T$ and $V$ of oscillations are given by (LAMB, 1932)

$$
2 T=\int_{0}^{l} S(\partial \xi / \partial t)^{2} d x ; 2 V=g \int_{0}^{l} b \eta^{2} d x \quad \text { (a) }
$$

in which $\xi$ and $\eta$ are horizontal and vertical displacement of the water and $S$ and $b$ are cross section and width normal to $x$-axis. The equation of continuity becomes

$$
\eta=-b^{-1} \partial(S \xi) / \partial x
$$

When we put $X=S \xi$, equations (a) are expressed by

$$
2 T=\int^{l}(\partial X / \partial t)^{2} S^{-1} d x ; 2 V=g \int_{0}^{l}(\partial X / \partial x)^{2} b^{-1} d x
$$

For a rectangular bay with a constant depth $h, X$ is given by a sum of normal functions which are sine functions about $x$. Thus

$$
X=\Sigma A_{n} \sin (n \pi x / l) \cos \left(2 \pi t / T_{n}\right)
$$

in which $A_{n}$ is a constant determined from the initial condition and $n$ is an integer for LS and a semi-integer for Bs. Periods $T_{n}$ are expressed by Merian's formula.

When cross sections of the bay are variable but deviations from the mean value of $S$ are small, the normal functions are expressed by (d) as the first approximation. Then, the constancy of total energy with time will give the proper period for each normal mode. In reverse, when the period thus determined is close to Merian's period, the mode of oscillations in the bay is considered to be similar to that of a rectangular bay.

Substituting one term of the right hand side of (d) into (a), we have

$$
\begin{aligned}
T & +V=A_{n}^{2}\left\{4 \pi^{2} T_{n}^{-2} \sin ^{2}\left(2 \pi t / T_{n}\right)\right. \\
& \times \int_{0}^{l} S^{-1} \sin ^{2}(n \pi x / l) d x+g(n \pi / l)^{2} \cos ^{2}\left(2 \pi t / T_{n}\right) \\
& \left.\times \int_{0}^{l} b^{-1} \cos ^{2}(n \pi x / l) d x\right\}
\end{aligned}
$$

The constancy of $T+V$ can be satisfied only when the coefficient of square sine and square cosine about time $t$ are equal. The condition gives the equation of $T_{n}$ expressed by (1) and (2) of the text.

\section{Appendix II. Energy of oscillations of water in a bay}

Consider a case when wind acts on the surface of a bay. By use of the same notations as in Appendix I, the equation of motion is given by

$$
\partial^{2} \xi / \partial t^{2}=-g \partial \eta / \partial x+\tau / h-k(\partial \xi / \partial t)
$$

in which $\tau$ is the $x$-component of wind stress, assumed to be uniform with depth, and $k$ is a frictional coefficient. Multiplying $\partial \xi / \partial t$ to both sides of (f) and integrating them over the whole volume of the water, we have

$$
\begin{aligned}
& \partial T / \partial t=-g \int_{0}^{D} S(\partial \xi / \partial t)(\partial \eta / \partial x) d x \\
& \quad+\int_{0}^{\imath} S \tau h^{-1}(\partial \xi / \partial t) d x-k \int_{0}^{\imath}(\partial \xi / \partial t)^{2} d x
\end{aligned}
$$

With the equation of continuity (b), the first 
term of the r.h.s. is transformed into

$$
\begin{gathered}
\int_{0}^{l} S \frac{\partial \xi}{\partial t} \frac{\partial \eta}{\partial t} d x=\left.\eta \frac{\partial \xi}{\partial t} S\right|_{0} ^{l}-\int_{0}^{l} \eta \frac{\partial}{\partial x}\left(\frac{\partial \xi}{\partial t} S\right) d x \\
=\left(\eta \frac{\partial \xi}{\partial t} S\right)_{l}+\frac{1}{2} \frac{\partial}{\partial t} \int_{0}^{l} b \eta^{2} d x
\end{gathered}
$$

where the subscript $l$ indicates the values at the inner end $x=l$ and the condition that $\partial \xi / \partial t=0$ at $x=0$ is used. The equation ( $\mathrm{g}$ ) becomes

$$
\begin{aligned}
& \frac{\partial}{\partial t}(T+V)=-g\left(\eta \frac{\partial \xi}{\partial t} S\right)_{l} \\
& \quad+\int_{0}^{l} b\left(\frac{\partial \xi}{\partial t}\right) \tau d x-\int_{0}^{l} k\left(\frac{\partial \xi}{\partial t}\right)^{2} S d x
\end{aligned}
$$

The first term of r.h.s. represents the energy transport at the mouth of the bay, the second term is the work done by wind stresses and the third term is the dissipation of energy by friction. The first and second term may be positive or negative according to phase lags of horizontal current to wind stresses or surface elevation at the mouth.

In a small bay $\tau$ is considered to be constant in the integral of r.h.s. of (i) except for strongly concentrated wind fields such as tornadoes. When the bay is not much deviated from a rectangular one, normal modes of oscillations are approximately expressed by sine functions. Thus we have

$$
\xi \sim a_{n}(t) \sin (n \pi x / l)
$$

in which $n$ is an integer for LS and a semiinteger for BS (Appendix 1). For the lowest mode, the second term of r.h.s. of (i) is equal to

$$
\left.\begin{array}{c}
\tau \dot{a}_{1}(t) \int_{0}^{l} b \sin (\pi x / l) d x,(\mathrm{LS}) ; \\
\tau \dot{a}_{0}(t) \int_{0}^{l} b \sin (\pi x / 2 l) d x,(\mathrm{BS})
\end{array}\right\}
$$

Thus the integral for LS becomes negligibly small when $b$ is almost constant, while the second integral of $(\mathrm{k})$ is equal to $2 \tau \dot{a}_{0}(t) b l \pi^{-1}$. This will explain that in Alligator Harbor (and similar bays with a mouth) oscillations of BS type are more frequently generated than those of LS type.

The relative importance of each term of r.h.s. in (i) may be estimated by comparing its absolute value computed for the lowest mode of BS. Under the condition that the bay is almost rectangular, absolute values $F_{1}, F_{2}$ and $F_{3}$ of the term substituted with a normal function $(\mathrm{j})$ are given by

$$
F_{1} \sim g \eta_{1} v S_{1}, \quad F_{2} \sim 2 l \pi^{-1} b^{2} \tau, \quad F_{3}=\frac{1}{2} k l S v^{2}
$$

in which $v=\left|\dot{a}_{0}(t)\right|$. The suffix 1 indicates the values at the mouth. Geometrical and physical constants in $F_{2}$ and $F_{3}$ represent the average values along the length of the bay.

In Alligator Harbor $S_{1}$ measured along the bar is $2.1 \times 10^{7} \mathrm{~cm}^{2}$. With $S=2.8 \times 10^{7} \mathrm{~cm}^{2}$ and $b=2 \times 10^{5} \mathrm{~cm}$, we have

$$
F_{1} / F_{2} \sim 0.21 \eta_{1} \tau^{-1}
$$

This is equal to one for $\eta_{1} \sim 13 \mathrm{~cm}$ and $\tau \sim 2.8$ $\mathrm{cm}^{2} / \mathrm{sec}^{2}$, the latter of which corresponds to wind speed of $10 \mathrm{~m} / \mathrm{sec}$. Thus energy transport through the mouth by long waves of rather small amplitudes is of the same order as the work done by a strong wind.

Autocorrelations and correlograms of $\xi$ or $\eta$ in a system described by the equation ( $f$ ) will be expressed by a function of damping oscillations, if the disturbing forces are random, as in the Brownian motion of a simple harmonic oscillator (WANG and UHLENBECK). Then, $k$ can be determined from logarithmic decrement of amplitudes of the correlogram. Disturbing forces in the example I discussed in Section 5 seem to satisfy the condition of randomness best. The $k$ value obtained from this correlogram is $1.5 \times 10^{-4} \mathrm{sec}^{-1}$, which gives

$$
F_{1} / F_{3} \sim 12 \eta_{1} v^{-1}
$$

This ratio becomes larger than 10 for a moderate value of $\eta_{1}$, because $v$ is usually less than $10 \mathrm{~cm} / \mathrm{sec}$. [The $k$-value determined from decrement of storm surges is $3 \times 10^{-5} \mathrm{sec}^{-1}$ in a bay about thirty miles long and thirty meters deep (ICHIYE, 1951)]. Therefore, the effect of the friction is small in Alligator Harbor.

This conclusion is not affected by introducing a frictional term $-\kappa u_{b}\left|u_{b}\right| h^{-1}$, instead of the third term of r.h.s. of (i), where $u_{b}$ is the velocity of bottom current and $\kappa$ is a constant. In this model normal functions are 
again expressed by sine functions approximately, although decrement with time is different from an exponential function (ICHIYe, 1955a). Thus we have

$$
F_{3} \sim v_{b}^{2} v \int_{0}^{l} \kappa b \sin ^{3}(\pi x / 2 l) d x \sim 4 \kappa b l v v_{b}^{2} / 3 \pi
$$

where $v_{b}$ is the amplitude of bottom current. Then by use of $\kappa=2 \times 10^{-3}$, which was applied to computation of tidal friction in the Irish Sea (TAYLOR, 1919), we have

$$
F_{1} / F_{3} \sim 1.6 \times 10^{3} \eta_{1} v_{b}{ }^{-2}
$$

[In waters more shallow than the Irish Sea $\kappa$ is larger than this value but bottom currents have phase lags to the mean currents (ICHIYE, 1955b)]. Therefore, this ratio (o) again indicates small contributions from the friction term compared with the energy transport through the mouth.

\section{Acknowledgement}

This work was aided by a contract between Office of Naval Research, Department of the Navy and Florida State University, Nonr-988 (06). Some auto-correlations of Table 4 were computed with IBM 650 of Computing Center at Florida State University.

\section{References}

Blackman, R. B. and J. W. TUKeY, 1958. The measurement of power spectra from the point of view of communications engineering, Bell System Tech. J. 37, 185-282 and 485-570.

BARTLETT, M. S., 1950. Periodgram analysis and continuous spectra, Biometrica, 37, 1-16.

BARTLETT, M. S., 1955. An introduction to stochas- tic processes, Cambridge University Press, 312 pp.

HONDA, K. et al., 1908. An investigation on the secondary undulation of oceanic tides, J. College of Sci., Imp. Univ. of Tokyo, 24, 1-113.

ICHIYE, T., 1950. On long waves caused by wind discontinuities, Mem. of Kobe Mar. Obs. 8.

ICHIYE, T., 1951. On the abnormal high water caused by the Typhoon "Jane". Reports of Oceanog. (Tokyo), 2 (2), 97-104, (in Japanese with English summary).

ICHIYE, T., 1955a. A short note on the dissipation of seiches, J. Oceanog. Soc. of Japan, 11 (3), 95-96.

ICHIYE, T., 1955b. On the friction in the tidal currents, Oceanog. Mag. (Tokyo), 7 (1), 55-77.

LAмв, H., 1932. Hydrodynamics, Cambridge University Press, 6th ed.

LANNING, J. H. and R. H. BATtin, 1956. Random processes in automatic control, McGraw-Hill Book Company, New York, 434 pp.

LettaU, H., 1932. Stehende Wellen als Ursachen ungestaltender Vorgange in Seen, Ann. d. Hydrog. u. marit. Met., Heft 6.

NeUmanN, G., 1948. Uber Resonanzschwingungen von Meeresbuchten und die Mündungskorrectur bei Seiches, D. Hydrog. Zeits., 1, 79-101.

OLSON, F. C. W., 1955. The hydrography of Alligator Harbor, Franklin County, Florida, Oceanog. Inst. Contr. No. 28 Florida St. Univ. (mimeographed).

SVERdRUP, H. U. et al, 1942. The oceans, Prentice-Hall, Inc., $1060 \mathrm{pp}$.

TAYLOR, G. I., 1919. Tidal friction in the Irish Sea, Trans. Roy. Soc. London, A 220, 1-23.

Thorade, H., 1931. Probleme der Wasserwellen, Probleme d. kosm. Physik, 13/14.

WANG, M. C. and G. E. UHLENBECK, 1945. On the theory of the Brownian motion II, Rev. Mod. Phys., 17 (3-4), 323-342.

Whittle, P., 1954. The statistical analysis of a seiche record, J. Mar. Res., 13 (1), 76-100. 